2011-01-01

\title{
Estimating the Efficacy of Mild Heating Processes taking into Account Microbial Non-linearities: a Case Study on the Thermisation of a Food Simulant
}

\author{
Vasilis Valdramidis \\ Technological University Dublin, vvaldram@gmail.com \\ Brijesh Tiwari \\ Manchester Metropolitan University \\ Patrick Cullen \\ Technological University Dublin, pj.cullen@tudublin.ie
}

See next page for additional authors

Follow this and additional works at: https://arrow.tudublin.ie/schfsehart

Part of the Applied Mathematics Commons

\section{Recommended Citation \\ Valdramidis,V.P. et al. (2010). Estimating the efficacy of mild heating processes taking into account microbial non-linearities: A case study on the thermisation of a food simulant. Food Control, 22(1), pp.137-142. doi:10.1016/j.foodcont.2010.05.007}

This Article is brought to you for free and open access by the School of Food Science and Environmental Health at ARROW@TU Dublin. It has been accepted for inclusion in Articles by an authorized administrator of ARROW@TU Dublin. For more information, please contact arrow.admin@tudublin.ie, aisling.coyne@tudublin.ie, gerard.connolly@tudublin.ie.

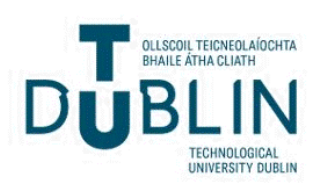




\section{Authors}

Vasilis Valdramidis, Brijesh Tiwari, Patrick Cullen, Alain Kondjoyan, and Jan Van Impe

This article is available at ARROW@TU Dublin: https://arrow.tudublin.ie/schfsehart/26 
Antenna \& High Frequency Research Centre

\title{
Articles
}

Dublin Institute of Technology

Year 2011

\section{Estimating the efficacy of mild heating processes taking into account microbial non-linearities: a case study on the thermisation of a food simulant}

\author{
Vasilis Valdramidis* ${ }^{*}$ Brijesh Tiwari ${ }^{\dagger} \quad$ P J. Cullen ${ }^{\ddagger}$
}

Alain Kondjoyan ${ }^{* *} \quad$ Jan Van Impe ${ }^{\dagger \dagger}$

*Dublin Institute of Technology, vvaldram@gmail.com

${ }^{\dagger}$ Manchester Metropolitan University

${ }^{\ddagger}$ Dublin Institute of Technology, pjcullen@dit.ie

**INRA, UR370 Qualité des Produits Animaux

${ }^{\dagger \dagger}$ Katholieke Universiteit Leuven

This paper is posted at ARROW@DIT.

http://arrow.dit.ie/ahfrcart/6 


\section{— Use Licence}

\section{Attribution-NonCommercial-ShareAlike 1.0}

You are free:

- to copy, distribute, display, and perform the work

- to make derivative works

Under the following conditions:

- Attribution.

You must give the original author credit.

- Non-Commercial.

You may not use this work for commercial purposes.

- Share Alike.

If you alter, transform, or build upon this work, you may distribute the resulting work only under a license identical to this one.

For any reuse or distribution, you must make clear to others the license terms of this work. Any of these conditions can be waived if you get permission from the author.

Your fair use and other rights are in no way affected by the above.

This work is licensed under the Creative Commons Attribution-NonCommercialShareAlike License. To view a copy of this license, visit:

- URL (human-readable summary):

http://creativecommons.org/licenses/by-nc-sa/1.0/

- URL (legal code):

http://creativecommons.org/worldwide/uk/translated-license 
1 Estimating the efficacy of mild heating processes taking into account microbial non-

2 linearities: a case study on the thermisation of a food simulant

3

4 V. P. Valdramidis ${ }^{1 *}$, A. H. Geeraerd ${ }^{2,3}$, B. K. Tiwari ${ }^{4}$, P.J. Cullen ${ }^{1}$, A. Kondjoyan ${ }^{5}$ and J.

5 F. Van Impe $e^{2,6}$

6

$7 \quad{ }^{1}$ School of Food Science \& Environmental Health, Dublin Institute of Technology, Cathal

8 Brugha Street, Dublin 1, Ireland.

$9{ }^{2} \mathrm{CPMF}^{2}$-Flemish Cluster Predictive Microbiology in Foods

$10{ }^{3}$ Division of Mechatronics, Biostatistics and Sensors (MeBioS), Department of

11 Biosystems (BIOSYST), Katholieke Universiteit Leuven, W. de Croylaan 42, B-3001

12 Leuven, Belgium.

13 ' ${ }^{4}$ Department of Food \& Tourism Management, Manchester Metropolitan University,

14 Manchester, M14 6HR, UK

$15{ }^{5}$ INRA, UR370 Qualité des Produits Animaux, F-63122 St Genès Champanelle, France.

$16{ }^{6} \mathrm{BioTeC}$ - Bioprocess Technology and Control, Department of Chemical Engineering,

17 Katholieke Universiteit Leuven, W. de Croylaan 46, B-3001 Leuven, Belgium

27 *Corresponding author: vvaldram@ gmail.com, Tel : +353 876331281 
29 Traditional and novel approaches for the calculation of the heat treatment efficiency are

30 compared in this work. The Mild Heat value ( $M H$-value), an alternative approach to the

31 commonly used sterilisation, pasteurisation and cook value $(F, P, C$-value), is calculated

32 to estimate the efficiency of a mild heat process. $M H$-value is the time needed to achieve

33 a predefined microbial reduction at a reference temperature and a known thermal resistant

34 constant, $z$, for log-linear or specific types of non log-linear microbial inactivation

35 kinetics. An illustrative example is given in which microbial inactivation data of Listeria

36 innocua CLIP 20-595 are used for estimating the inactivation parameters under

37 isothermal conditions of 58,60, 63 and $66^{\circ} \mathrm{C}$ by the use of the log-linear and the Geeraerd

38 et al., (2000) model. Thereafter, dynamic temperature profiles (targeting at 54 and $57^{\circ} \mathrm{C}$ )

39 representing milk thermisation are exploited for illustrating the application of $M H$-value.

40 Finally, the equivalent holding times of different temperatures are calculated taking into

41 account the observed non-linearity. 


\section{Introduction}

60 When microbial inactivation processes are described as log-linear, a linear relationship

61 between the logarithm of the microbial population level (in absolute value or relative to

62 the initial value) and the treatment time are considered. If log-linearity is indeed being

63 observed, the thermal death time, $F$-value is used as a basis for comparing heat

64 sterilisation procedures. The $F$-value (Eq. (1)) (Ball, 1923) is defined as the time required

65 in order to achieve a specific reduction in microbial numbers at a given temperature and it

66 thus represents the total time-temperature combination received by a food. Similarly, the

$67 P$-value and the $C$-value are the corresponding thermal death value under pasteurisation

68 and cooking conditions, respectively (Pittia, Furlanetto, Maifreni, Mangina \& Rosa, 69 2008).

$$
F_{T_{\text {ref }}}=\int_{0}^{t} 10^{\left(T(t)-T_{r e f}\right) / z} d t
$$

71 Eq. (1), as mentioned above, is valid if the survival curve obeys first order kinetics.

72 Despite the world-wide use of this approach especially in the canning industry for the so-

73 called '12D process' of the proteolytic strains (Group I) of Clostridium botulinum spores

74 (Stumbo, 1965; ICMSF, 1996), a lot of deviations from log-linearity have been observed

75 (e.g., Corradini, Normand and Peleg (2005)). As other authors acknowledge, the success

76 of the canning industry in using the $F$-value as a measure of the heat processes efficacy

77 could be attributed to over-processing and not to the calculation method's correctness

78 (Corradini, Normand \& Peleg, 2006). These deviations are evident particularly at lower

79 temperatures than the sterilisation ones, and for vegetative cells (Valdramidis, Geeraerd,

80 Bernaerts \& Van Impe, 2006; Huang, 2009; Miller, Gil, Brandao, Teixeira \& Silva, 81 2009).

82 A mild heat treatment often applied in the dairy industry is thermisation of milk 83 destinated for cheese making. This process has milder effects on the raw milk flora and 84 the functionality of milk caseins and salts than pasterurisation (Samelis et al., 2009). 85 Thermisation is applied at temperatures that range between 52 to $67^{\circ} \mathrm{C}$ for a treatment 86 time of few seconds, i.e., 20 s, to about half an hour (Zehetner, Bareuther, Henle \& 
87 Klostermeyer, 1996; McKellar \& Piyasena, 2000; Christiansen, Nielsen, Vogensen, 88 Brogren \& Ardo, 2006; Levieux, Geneix \& Levieux, 2007; Samelis et al., 2009) while 89 according to the council directive 92/46/EEC of 16 June 1992, thermisation is the heating 90 of raw milk for at least $15 \mathrm{~s}$ at a temperature between $57^{\circ} \mathrm{C}$ and $68^{\circ} \mathrm{C}$ such that after 91 treatment the milk shows a positive reaction to the phosphate test.

92 When focusing on microbiological safety, the accurate description of the kinetics of the 93 target pathogenic microorganism (or a surrogate of a pathogenic target microorganism) is 94 essential. Milk designed for milk based products should receive a heat treatment process 95 to reduce the probability of survival of L. monocytogenes by at least a factor of $10^{4}$ (FIL96 IDF, 1994). Taking a safety margin into account, usually a log reduction of 6 is 97 considered (Claeys, Van Loey \& Hendrickx, 2002). Estimation of the time to achieve this $98 \log$ reduction is a very critical issue for the design and application of an efficient heat 99 treatment.

100 Over the last 30 years a number of inactivation models have been developed aiming at 101 describing non-log-linear microbial inactivation kinetics. An overview of inactivation 102 models portraying eight common type curves is given by Geeraerd, Valdramidis and Van 103 Impe, (2005). The development of these models raises the need of redefining the thermal 104 death time by a modelling approach that includes the possibility of non-log-linear 105 microbial survival curves, especially in cases of mild heat treatments, like thermisation.

106 Recent studies in the broader field of heat processing suggested alternative approaches 107 for evaluating the efficacy of a process when assuming that microbial heat resistances 108 follow a weibulian frequency distribution model (Mafart, Couvert, Gaillard \& Leguerinel, 109 2002; Corradini et al., 2006; Sant'Ana, Rosenthal \& Massaguer, 2009). Nevertheless, 110 these approaches take into account only two types of non-log-linearity (i.e., concave, 111 convex) and are not retaining classical parameters (like the $z$-value) for evaluating the 112 achieved microbial reduction.

113 The main objective of this study was to calculate a value for the efficacy of a mild 114 heating process similar to thermisation in which inactivation kinetics are not log-linear 115 and to test the approach for the mild heat treatment of thermisation for a (model) liquid 116 food system. L. innocua is considered as the surrogate safety target attributed for the 117 studied simulant liquid food. The final objective was to develop an alternative (to the 
118 classical $F, P, C$ values) mathematical expression in order to evaluate the efficiency of a

119 thermal treatment if additional environmental or physiological factors are considered.

\section{Materials and methods}

\section{Modelling approaches}

125

126 In this study a general expression of the microbial inactivation kinetics (Van Impe, 127 Poschet, Geeraerd \& Vereecken, 2005), was considered. This expression is described as 128 follows.

$$
\frac{d N}{d t}=-k(N,<e n v>,<\text { phys }>) \cdot N
$$

$130 N$ is the cell density of the microbial species $(\mathrm{cfu} / \mathrm{mL}),<e n v>$ denotes the actual 131 (micro)environmental conditions (not or only slightly influenced by the microbial 132 evolution) such as temperature, high pressure, salt concentration, water activity, etc and $133<$ phys > is the physiological state of the species, for instance, as influenced by the 134 temperature history. This expression can then be coupled with differential equations that 135 describe the dynamics of the physiological state parameters e.g., Geeraerd, Herremans \& 136 Van Impe, (2000).

137 A sound set of differential equations, which is a sub-case of Eq. (2), and describes the 138 microbial inactivation kinetics by incorporating physiological adjustments during the 139 microbial inactivation experiments is the dynamic, non-log-linear model of (Geeraerd et 140 al., 2000). This model is constructed for microbial inactivation by mild heating. 


$$
\begin{aligned}
& \frac{d N}{d t}=-k_{\max } \cdot\left(\frac{1}{1+C_{c}}\right) \cdot\left(1-\frac{N_{r e s}}{N}\right) \cdot N \\
& \frac{d C_{c}}{d t}=-k_{\max } \cdot C_{c}
\end{aligned}
$$

143 Herein, $N$ represents the microbial cell density [cfu/mL], $C_{c}$ is related to the physiological 144 state of cells [-], $k_{\max }$ denotes the specific inactivation rate [1/min] and $N_{\text {res }}$ the residual 145 population density [cfu/mL]. This is a model for describing non-linearities that 146 incorporate shoulder and/or tailing effects and it automatically reduces to log-linear 147 inactivation kinetics if the data do not include these effects. Although there are more 148 known survivor curve shapes for vegetative bacterial cells (Geeraerd et al., 2005) the 149 current modelling approach is built based on the features of the microbial data of the case 150 study presented hereunder.

151 Thermal inactivation parameters, i.e., the asymptotic decimal reduction time (AsymD152 value) (Juneja, Eblen \& Marks, 2001) and the thermal resistance constant ( $z$-value), i.e., 153 the temperature change required to achieve a tenfold change in $A s y m D$-value, integrated 154 into the Bigelow model (Eq. (5)) yields predictions for the specific inactivation rate at a 155 given temperature.

156

$$
k_{\text {max }}(T)=\frac{\ln 10}{A s y m D_{r e f}} \cdot \exp \left(\frac{\ln 10}{z} \cdot\left(T-T_{\text {ref }}\right)\right)
$$

158 Herein, AsymD $D_{\text {ref }}[\mathrm{min}]$ is the asymptotic decimal reduction time at the reference 159 temperature $T_{r e f}\left[{ }^{\circ} \mathrm{C}\right]$. Observe that $D_{\text {ref }}$ of the original Bigelow equation is replaced by $160 A s y m D_{r e f}$ as it describes the negative inverse of the slope of the log linear part of the 161 inactivation curve. 
163 Eqs (2)-(5) are the main set of equations for calculating the mild heat pasteurisation 164 value, $M H$-value (see Results).

165 The explicit version of Eqs (3)-(5) is as follows (Eq. (5) is inserted in the explicit version 166 of Eqs (3), (4)).

$$
\begin{gathered}
\log (N(t))=\log \left(\left(10^{\log (N(0))}-10^{\log (\text { Nres })}\right) \cdot \exp \left(-\frac{\ln 10}{A s y m D_{r e f}} \cdot \exp \left(\frac{\ln 10}{z} \cdot\left(T-T_{r e f}\right)\right) \cdot t\right)\right. \\
\left.\cdot \frac{1+10^{\log \left(C_{c}(0)\right)}}{1+10^{\log \left(C_{c}(0)\right)} \cdot \exp \left(-\frac{\ln 10}{A s y m D_{r e f}} \cdot \exp \left(\frac{\ln 10}{z} \cdot\left(T-T_{r e f}\right)\right) \cdot t\right)}+10^{\log (\text { Nres })}\right)(6)
\end{gathered}
$$

169 In order to demonstrate the validity of the modelling approach that evaluates the $M H$ -

170 value some illustrative examples are given. Firstly, a dynamic profile representing 171 thermisation was generated and secondly, the static temperatures of different time 172 treatments for achieving the same microbial reduction were evaluated. Both studies were 173 performed for a given microbial inactivation kinetics (see hereunder).

175 Case study

176 Microbial essay

178 The studied methodological approach is illustrated based on data of microbial kinetics of 179 Listeria innocua CLIP 20-595 originating from Peroval, Portanguen and Kondjoyan, 180 (2004). Summarising, the heat resistance of Listeria innocua was studied by the use of $181 \quad 100 \mu \mathrm{L}$ of the cell suspension sealed in sterile glass capillary tubes. The tubes were 182 immersed in a thermostat controlled circulating water bath at temperatures of 58, 60, 63, 18366,68 and $70^{\circ} \mathrm{C}$. Come-up times, which were in any case very small, were included as 184 part of the total heating time used to calculate the inactivation parameters. Decimal serial 185 dilutions of the samples were made in TS medium and surface plated in duplicate on 
PALCAM agar (Merck). Plates were incubated for $24-48 \mathrm{~h}$ at $37^{\circ} \mathrm{C}$ and colony-forming units (cfu) were enumerated. Heat resistance experiments were carried out in triplicate.

\section{Parameter estimation}

The microbial inactivation parameters under the isothermal conditions were estimated:

(i) by taking into account the appearing shoulder and tailing effects (Eqs (3), (4)),

(ii) by assuming first order inactivation kinetics for all the inactivation data (Eq.

In order to identify the model parameters a so called global identification making use of all static experiments in one step was implemented. So for example in the case (i) Asym $_{\text {ref }}, \mathrm{z}, \log C_{c}(0)$, and $\log N(0)$ (one for each temperature), $\log N_{\text {res }}$ (one for each temperature) (Eq. (6)) were estimated. The selected reference temperature was chosen to be equal to $62^{\circ} \mathrm{C}$, as the optimal choice to minimize the uncertainty on Asym $D_{r e f}$ was in

212 Van Loey, Hendrickx \& Van Impe, 2005). Parameters were estimated based on the 213 minimisation of the Sum of Squared Errors (SSE). 
218 Thermisation experiments were conducted in a pilot scale retort following the same

219 procedure described in (Patras, Tiwari, Brunton \& Butler, 2009). The prepared cans $(75 \times$ $220110 \mathrm{~mm}$, WEI/WEISS03, Germany) were filled with the same suspension used for the 221 microbial studies, i.e., Tryptone-Salt (TS) medium $0.1 \% \mathrm{w} / \mathrm{v}, 0.85 \% \mathrm{w} / \mathrm{v} \mathrm{NaCl}$ ) and were

222 loaded into the pilot scale retort (Barriquand Steriflow, Roanne, France). Sample core 223 temperature profiles were recorded during the process, using an Ellab E-Val TM TM9608 224 data module (Ellab [UK] Ltd., Norfolk, England) connected to a laptop. A standard Ellab 225 SSA-12080-G700-TS temperature probe was inserted through an Ellab GKM-13009$226 \mathrm{C} 020$ packing gland $(20 \mathrm{~mm})$ into the a can to record the temperature cycle. Temperature 227 was monitored every $10 \mathrm{~s}$. The samples were heated targeting at a final temperature of 54 228 and $57^{\circ} \mathrm{C}$. Prior to any canning experiment, all Ellab unit probes were calibrated against a 229 JOFRA (ATC-155B) calibration unit.

\section{Results \& Discussion}

Defining the MH-value

235 a reference temperature and a known thermal resistant constant, $z$, when microbial 236 inactivation kinetics is not linear. Mathematically, this expression can be calculated by 237 deriving the achieved microbial reduction at given temperature conditions. So if the non238 log-linear microbial kinetics are described by the (Geeraerd et al., 2000) Eqs (3)-(5) then 239 the achieved microbial reduction is given as follows.

$$
\int_{0}^{t} \frac{d N(t)}{N(t)}=-\int_{0}^{t} k_{\max } \cdot\left(\frac{1}{1+C_{c}}\right) \cdot\left(1-\frac{N_{r e s}}{N}\right) \cdot d t
$$

$$
\ln \left(\frac{N(t)-N_{r e s}}{N(0)-N_{r e s}}\right)=-\frac{\ln 10}{\operatorname{Asym~D~}_{\text {ref }}} \cdot \int_{0}^{t} \exp \left(\frac{\ln 10}{z} \cdot\left(T-T_{r e f}\right)\right) \cdot\left(\frac{1}{1+C_{c}(t)}\right) \cdot d t
$$

242 with $C_{c}(t)$ described by Eq (4) 


$$
\frac{d C_{c}}{d t}=-k_{\max } \cdot C_{c}
$$

244 Similar to the pasteurisation/sterilisation/cooling principles $(P / F / C$-values) the mild heat 245 value $(M H$-value) can be calculated in the following form when considering non246 isothermal conditions and microbial parameter identification originates from microbial 247 data that incorporate shoulder and/or tailing effects.

$$
M H=\int_{0}^{t} \ln 10 \cdot \exp \left(\frac{\ln 10}{z} \cdot\left(T(t)-T_{r e f}\right)\right) \cdot\left(\frac{1}{1+C_{c}(t)}\right) \cdot d t(7)
$$

$$
\frac{d C_{c}}{d t}=-k_{\max }(T(t)) \cdot C_{c}(t)
$$

250 Observe that the $M H$-value is given by a set of two equations in which the second 251 describes the evolution of the microbial physiological state of the cells. Under isothermal 252 conditions for an equivalent temperature $T_{e q}$ Eqs (7), (8) will look as follows (the explicit 253 version is given).

$$
\begin{aligned}
& M H=\ln 10 \cdot \exp \left(\frac{\ln 10}{z} \cdot\left(T_{e q}-T_{r e f}\right)\right) \\
& \left(t+\frac{1}{\frac{\ln 10}{A s y m D_{r e f}} \cdot \exp \left(\frac{\ln 10}{z} \cdot\left(T_{e q}-T_{r e f}\right)\right)} \cdot \ln \left(\frac{\left.1+C_{c}(0) \cdot \exp \left(-\frac{\ln 10}{A s y m D_{r e f}} \cdot \exp \left(\frac{\ln 10}{z} \cdot\left(T_{e q}-T_{r e f}\right)\right) \cdot \mathrm{t}\right)\right)}{C_{c}(0)+1}\right)\right)(9)
\end{aligned}
$$

258 where instead of $T(t)$ the equivalent temperature $T_{e q}$ is chosen, in which the same 259 microbial inactivation is achieved for the same time treatment (see Welt, Teixeira, 260 Balaban, Smerage and Sage (1997) for a similar example when considering first order 261 inactivation kinetics). 


\section{Microbial parameter identification}

265 A so called global identification making use of all static experiments (presented in Figure

266 1) in one step was implemented. Parameters estimated taking into account the non-

267 linearities are presented in Table 1. In the case that shoulder and tailing effects were not

268 considered, Eq. (3) reduces to the classical first order inactivation model. Similarly the

269 inactivation parameters were estimated for that case study and the results are illustrated in

270 Table 2. As expected, when assuming first order inactivation kinetics only for the log-

271 linear portion of the inactivation kinetics the estimated microbial parameters i.e.,

$272 \operatorname{Asym} D_{62}, z$, coincide with those estimated during the non-log-linear regression analysis

273 (Table 3). The obtained $z$-values appear to be rather high but they seem to be on the range

274 of the estimated $z$-value $\left(z=7^{\circ} \mathrm{C}\right)$ of L. monocytogenes obtained for various food

275 products (van Asselt \& Zwietering, 2006).

276 The conducted thermisation experiments resulted on the temperature profiles given in

277 Figure 2. The targeting final temperature of 54 and $57^{\circ} \mathrm{C}$ was achieved in less than 20

278 minutes. The effect of non-log-linearity on describing the microbial inactivation kinetics

279 was evaluated for both tested temperature profiles (by coupling these profiles with the

280 microbial modelling models) (see Figure 2). These predictions are performed considering

281 that inactivation of L. innocua is initiated at temperatures higher than $47^{\circ} \mathrm{C}$ (Valdramidis

282 et al., 2008).

283 Depending on the severity of the temperature treatment the curves are diverging (see

284 Figure 2). Considering that non-log-linearity described better the microbial data at hand it

285 is evident that at temperature profiles targeting at $57^{\circ} \mathrm{C}$ an overestimation of the achieved

286 microbial reductions is predicted from the classical log-linear modelling approaches

287 (Figure 2). However for a target temperature of $54^{\circ} \mathrm{C}$ only when considering the

288 microbial parameters estimated from a log-linear-regression of all the data results in the

289 less conservative predictions for the achieved microbial reduction (Figure 2).

290 Further on, the developed methodological approach of the $M H$-value is tested for 291 evaluating the efficiency of the dynamic temperature treatments when targeting at a

292 specific microbial log reduction. Therefore, for a set of chosen equivalent temperatures, 
293 i.e., $52,55,57^{\circ} \mathrm{C}$, the $M H$-values are estimated by the use of Eq. (9) when considering 294 the three approaches of linearity and non-linearity. The desired microbial log reduction of 295 L. innocua was set to 4 logs (FIL-IDF, 1994) and 6 logs (safety margin (Claeys et al., 296 2002)). Observe that the derivation of $M H$-value (or the so called equivalent holding 297 time, $t_{e q}$ ) when considering log-linear inactivation were calculated by omitting the factor 298 which describes the physiological state of the cells in Eq. (9). Given that non-log-linearity 299 describes more accurately than log-linearity the static microbial inactivation data and 300 considering that the $t_{e q}$ from the non-log-linear inactivation kinetics is the true one some 301 observations can be drawn from the results presented in Figure 3. On one hand when 302 assuming log-linear kinetics at the examined temperature range, i.e. case (iii), an over303 processing treatment seems to happen which is more evident when targeting a $4 \log$ 304 reduction. On the other hand when considering log-linear inactivation kinetics only for 305 the log-linear portion of the data, an under-processing effect is quite pronounced. These 306 results highlight that process efficiency can be wrongly calculated if assuming log307 linearity for non-log-linear inactivation data. It should be noted that similar over308 processing effect in case of log-linear inactivation kinetics at sterilisation temperatures 309 for microbial spores were observed by Corradini et al., (2006). In this study it appears 310 that the different types of log-linearity as well as the temperature range tested are both 311 influencing the estimated $M H$ values. Inactivation temperature levels higher than $57^{\circ} \mathrm{C}$ 312 are expected to result in an interchange of the over- and under- processing regions (as the 313 lines depicted in Figure 3 are not parallel) while at much higher temperatures the 314 shoulder and tailing effects are less evident.

315 The $M H$-value can be written in a more general form as follows (from Eqs (2), (7)).

$$
M H=A s y m D_{r e f} \cdot \int_{0}^{t} k(N,<e n v>,<p h y s>) d t
$$

317 The advantages of this equation, if compared with previous literature studies, are twofold:

318 (i) it takes into account non-log-linearity and (ii) it can easily be extended with respect to 319 other environmental conditions or/and adjusted according to the microbial physiological 320 state. Although similar concepts have been discussed in the literature like the method of 321 Paired Equivalent Isothermal Exposures (PEIE) (Welt et al., 1997), they considered 
322 irreversible first-order inactivation. Thus, in the case of microbial kinetics exhibiting a

323 shoulder effect, PEIE method would assume a straight line between two points on the

324 actual survivor curve. Nevertheless, there are recent studies that evaluate the non-log-

325 linearity effects by assuming convex, concave or log-linear kinetics (Mafart et al., 2002;

326 Corradini et al., 2006; Sant'Ana et al., 2009). If these approaches are compared with the

327 developed $M H$-value then it can be seen that the parameters of the classical Bigelow

328 approach are retained in the current approach while the observed non-log-linearity, i.e.,

329 shoulder, tailing effects are described by additional factors. Particularly, the non-log-

330 linearity effect in those studies is described by the parameters $\delta$ and $p$ and $b$ and $n$,

331 respectively, which do not discriminate between log-linear and non-log-linear parts of the

332 inactivation kinetics. The advantage of the current approach is that the additional

333 parameters can be interpreted independently and Eq. (11) can be further specified

334 depending on the case-study at hand, for example, when more (environmental or

335 physiological) factors are considered.

\section{Future work}

339 Further studies on coupling microbial inactivation kinetics with heat transfer phenomena

340 especially for non-homogeneous products (including solid foods) are of interest for

341 designing similar thermal process. Investigation with other microorganisms and cases that

342 result in high non-log-linearity and comparison with the classical acceptable approaches

343 will work as additional validation of the developed modelling approach. For industrial

344 application purposes a comparative economical impact of the calculation of different

345 thermal death values is also of interest as it can avoid over and under-processing

346 schemes. 


\section{References}

Ball, C. O. (1923). Thermal Process Time for Canned Food. National Research Council

357 Bulletin, 7(37).

358 Christiansen, P., Nielsen, E. W., Vogensen, F. K., Brogren, C. H., \& Ardo, Y. (2006).

359 Heat resistance of Lactobacillus paracasei isolated from semi-hard cheese made of pasteurised milk. International Dairy Journal, 16(10), 1196-1204. integrators for heat treatment of milk. Trends in Food Science \& Technology, 13(9-10), 293-311.

Corradini, M. G., Normand, M. D., \& Peleg, M. (2005). Calculating the efficacy of heat sterilization processes. Journal of Food Engineering, 67(1-2), 59-69.

Corradini, M. G., Normand, M. D., \& Peleg, M. (2006). Expressing the equivalence of non-isothermal and isothermal heat sterilization processes. Journal of the Science of Food and Agriculture, 86(5), 785-792.

FIL-IDF (1994). Recommendations for the hygienic manufacture of milk and milk based products. Brussels, International Dairy Federation.

Geeraerd, A. H., Herremans, C. H., \& Van Impe, J. F. (2000). Structural model requirements to describe microbial inactivation during a mild heat treatment. International Journal of Food Microbiology, 59(3), 185-209.

Geeraerd, A. H., Valdramidis, V., \& Van Impe, J. F. (2005). GInaFiT, a freeware tool to assess non-log-linear microbial survivor curves. International Journal of Food Microbiology, 102(1), 95-105.

Huang, L. H. (2009). Thermal inactivation of Listeria monocytogenes in ground beef under isothermal and dynamic temperature conditions. Journal of Food Engineering, 90(3), 380-387.

ICMSF (1996). ICMSF: Microorganisms in Food 5, Characteristics of microbial pathogens London, Blackie Acedmic and professional.

Juneja, V. K., Eblen, B. S., \& Marks, H. M. (2001). Modeling non-linear survival curves to calculate thermal inactivation of Salmonella in poultry of different fat levels. International Journal of Food Microbiology, 70(1-2), 37-51.

Levieux, D., Geneix, N., \& Levieux, A. (2007). Inactivation-denaturation kinetics of bovine milk alkaline phosphatase during mild heating as determined by using a monoclonal antibody-based immunoassay. Journal of Dairy Research, 74(3), 296-301.

Mafart, P., Couvert, O., Gaillard, S., \& Leguerinel, I. (2002). On calculating sterility in thermal preservation methods: application of the Weibull frequency distribution model. International Journal of Food Microbiology, 72(1-2), 107-113.

McKellar, R. C., \& Piyasena, P. (2000). Predictive modelling of inactivation of bovine milk alpha-L-fucosidase in a high-temperature short-time pasteurizer. International Dairy Journal, 10(1-2), 1-6.

Miller, F. A., Gil, M. M., Brandao, T. R. S., Teixeira, P., \& Silva, C. L. M. (2009). 396 and growth phase. Food Control, 20(12), 1151-1157. 
Patras, A., Tiwari, B. K., Brunton, N. P., \& Butler, F. (2009). Modelling the effect of different sterilisation treatments on antioxidant activity and colour of carrot slices during storage. Food Chemistry, 114(2), 484-491.

400 Peroval, C., Portanguen, S., \& Kondjoyan, A. (2004). Thermal inactivation of Listeria innocua CLIP 20-595 in broth or attached to Teflon surfaces. Food Factory of the Future, Laval, France.

Pittia, P., Furlanetto, R., Maifreni, M., Mangina, F. T., \& Rosa, M. D. (2008). Safe cooking optimisation by F-value computation in a semi-automatic oven. Food Control, 19(7), 688-697.

Poschet, F., Geeraerd, A. H., Van Loey, A. M., Hendrickx, M. E., \& Van Impe, J. F. (2005). Assessing the optimal experiment setup for first order kinetic studies by Monte Carlo analysis. Food Control, 16(10), 873-882.

Samelis, J., Lianou, A., Kakouri, A., Delbes, C., Rogelj, I., Bogovic-Matijasic, B., \& Montel, M. C. (2009). Changes in the Microbial Composition of Raw Milk Induced by Thermization Treatments Applied Prior to Traditional Greek Hard Cheese Processing. Journal of Food Protection, 72(4), 783-790.

Sant'Ana, A. S., Rosenthal, A., \& Massaguer, P. R. (2009). Heat resistance and the effects of continuous pasteurization on the inactivation of Byssochlamys fulva ascospores in clarified apple juice Journal of Applied Microbiology, 107(1), 197-209.

Stumbo, C. R. (1965). Thermobacteriology in food processing. New York, Academic Press.

Valdramidis, V. P., Geeraerd, A. H., Bernaerts, K., \& Van Impe, J. F. (2006). Microbial dynamics versus mathematical model dynamics: The case of microbial heat resistance induction. Innovative Food Science \& Emerging Technologies, 7(1-2), 80-87.

Valdramidis, V. P., Peroval, C., Portanguen, S., Verhulst, A. J., Van Impe, J. F. M., Geeraerd, A. H., \& Kondjoyan, A. (2008). Quantitative evaluation of thermal inactivation kinetics of free-floating versus surface-attached Listeria innocua cells. Food and Bioprocess Technology, 1(3), 285-296.

van Asselt, E. D., \& Zwietering, M. H. (2006). A systematic approach to determine global thermal inactivation parameters for various food pathogens. International Journal of Food Microbiology, 107(1), 73-82.

Van Impe, J. F., Poschet, F., Geeraerd, A. H., \& Vereecken, K. M. (2005). Towards a novel class of predictive microbial growth models. International Journal of Food Microbiology, 97-105.

Welt, B. A., Teixeira, A. A., Balaban, M. O., Smerage, G. H., \& Sage, D. S. (1997). An hypothesis paper - Iterative method for kinetic parameter estimation from dynamic thermal treatments. Journal of Food Science, 62(1), 8-14.

Zehetner, G., Bareuther, C., Henle, T., \& Klostermeyer, H. (1996). Inactivation of endogenous enzymes during heat treatment of milk. Netherlands Milk and Dairy Journal, 50(2), 215-226. 
443 Table 1. Parameter estimates (and their standard errors) derived from the non-log-linear 444 regression of Eqs 3-5 on the microbial data performed in capillary tubes at temperatures $445 \quad 58-66^{\circ} \mathrm{C}$.

446

\begin{tabular}{lll}
\hline Asym $_{62}[\mathrm{~min}]$ & $\mathrm{z}\left[{ }^{\circ} \mathrm{C}\right]$ & $\log \left(C_{c}(0)\right)[-]$ \\
$0.32 \pm 0.01$ & $9.02 \pm 0.24$ & $1.14 \pm 0.23$
\end{tabular}

\begin{tabular}{llll}
\hline $\log N(0)_{58}[-]$ & $\log N(0)_{60}[-]$ & $\log N(0)_{63}[-]$ & $\log N(0)_{66}[-]$ \\
$8.99 \pm 0.14$ & $8.77 \pm 0.14$ & $9.01 \pm 0.14$ & $9.05 \pm 0.16$ \\
\hline $\log N_{\text {res58 }}[-]$ & $\log N_{\text {res60 }}[-]$ & $\log N_{\text {res63 }}[-]$ & $\log N_{\text {res66 }}[-]$ \\
$2.89 \pm 0.25$ & $3.59 \pm 0.14$ & $2.77 \pm 0.29$ & $2.77 \pm 0.25$
\end{tabular}

Table 2. Parameter estimates (and their standard errors) derived from a linear regression of the microbial data performed in capillary tubes at temperatures $58-66^{\circ} \mathrm{C}$.

\begin{tabular}{llll}
\hline Asym $_{62}[\mathrm{~min}]$ & $\mathrm{z}\left[{ }^{\circ} \mathrm{C}\right]$ & \\
$0.41 \pm 0.13$ & $8.75 \pm 0.29$ & & \\
\hline $\log N(0)_{58}[-]$ & $\log N(0)_{60}[-]$ & $\log N(0)_{63}[-]$ & $\log N(0)_{66}[-]$ \\
$9.19 \pm 0.19$ & $9.31 \pm 0.24$ & $9.23 \pm 0.19$ & $9.38 \pm 0.26$
\end{tabular}

Table 3. Parameter estimates (and their standard errors) derived from a linear regression of the microbial data when assuming first order inactivation kinetics only for the loglinear portion of the inactivation kinetics.

459
$\operatorname{Asym} D_{62}[\mathrm{~min}]$
$\mathrm{z}\left[{ }^{\mathrm{O}} \mathrm{C}\right]$
$0.32 \pm 0.01$
$9.02 \pm 0.24$ 

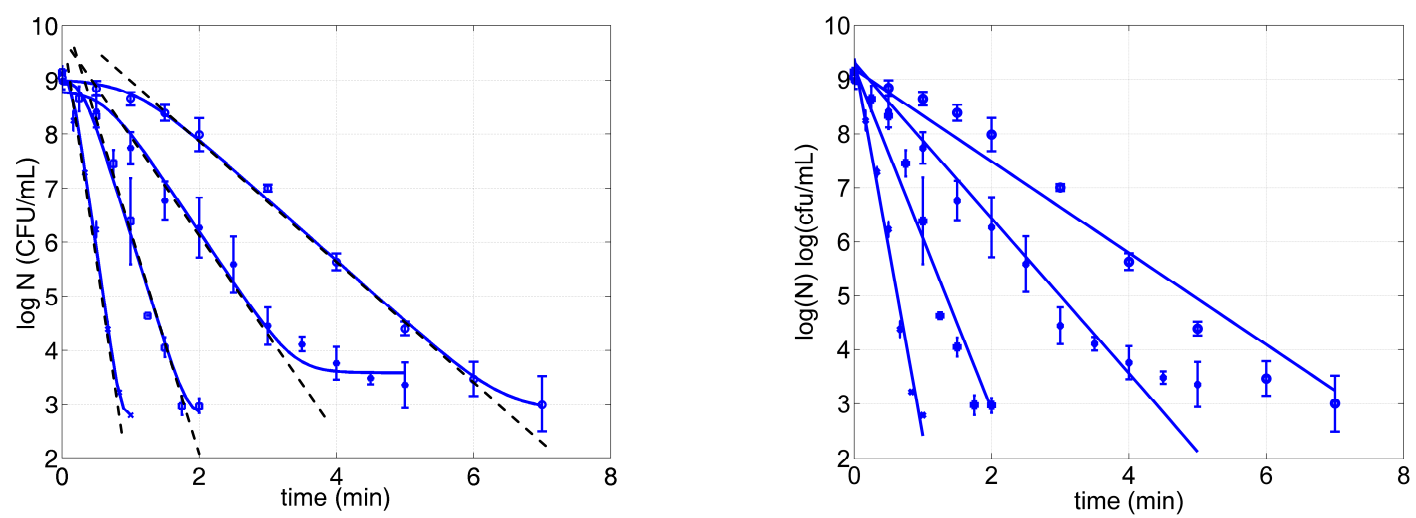

Figure 1. Regression analysis by taking into account shoulder and tailing effects (Left Figure, continuous line), by assuming first order inactivation kinetics only for the loglinear portion of inactivation (Left Figure, dashed line), by assuming first order inactivation kinetics for all inactivation data (Right Figure).
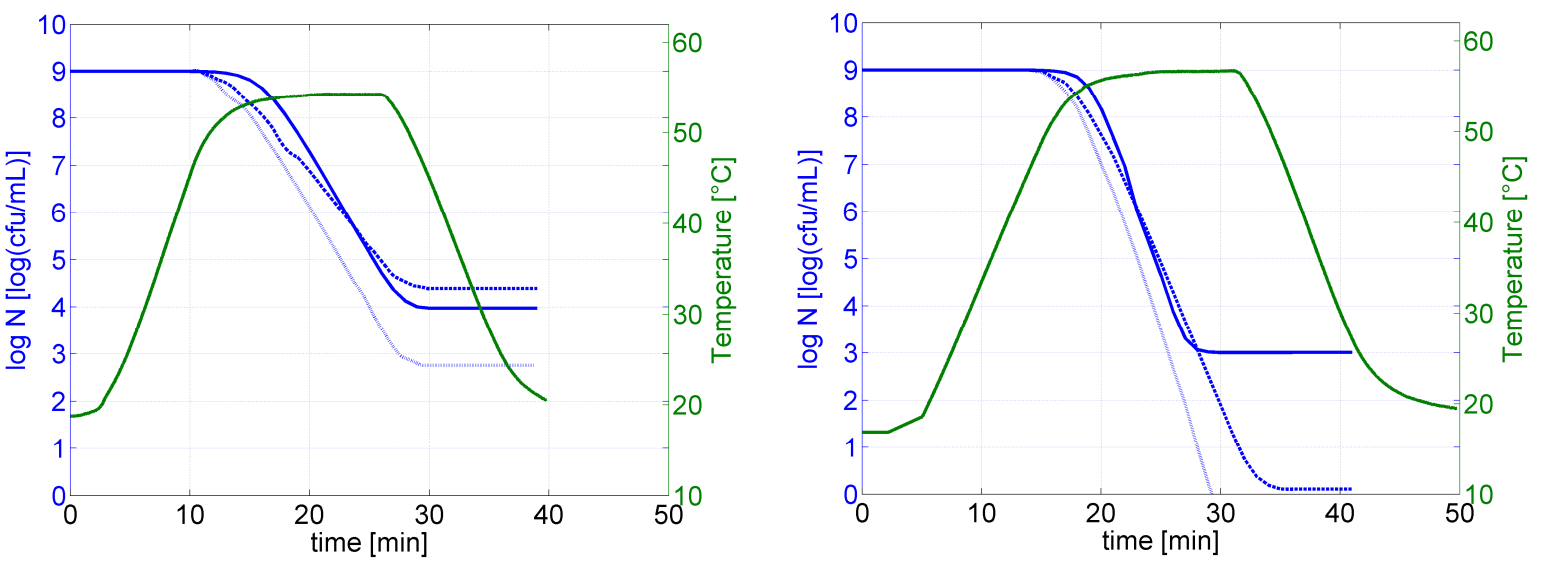

Figure 2. Dynamic temperature profile of a mild heat process representing thermisation with a target temperature of $54^{\circ} \mathrm{C}$ (Left), $57^{\circ} \mathrm{C}$ (Right) and associated microbial simulations (i) (considering non-log-linearity), continuous line, case (ii) (considering log499 linearity when taking the log-linear portion of the data), dotted line, case (iii) (considering 

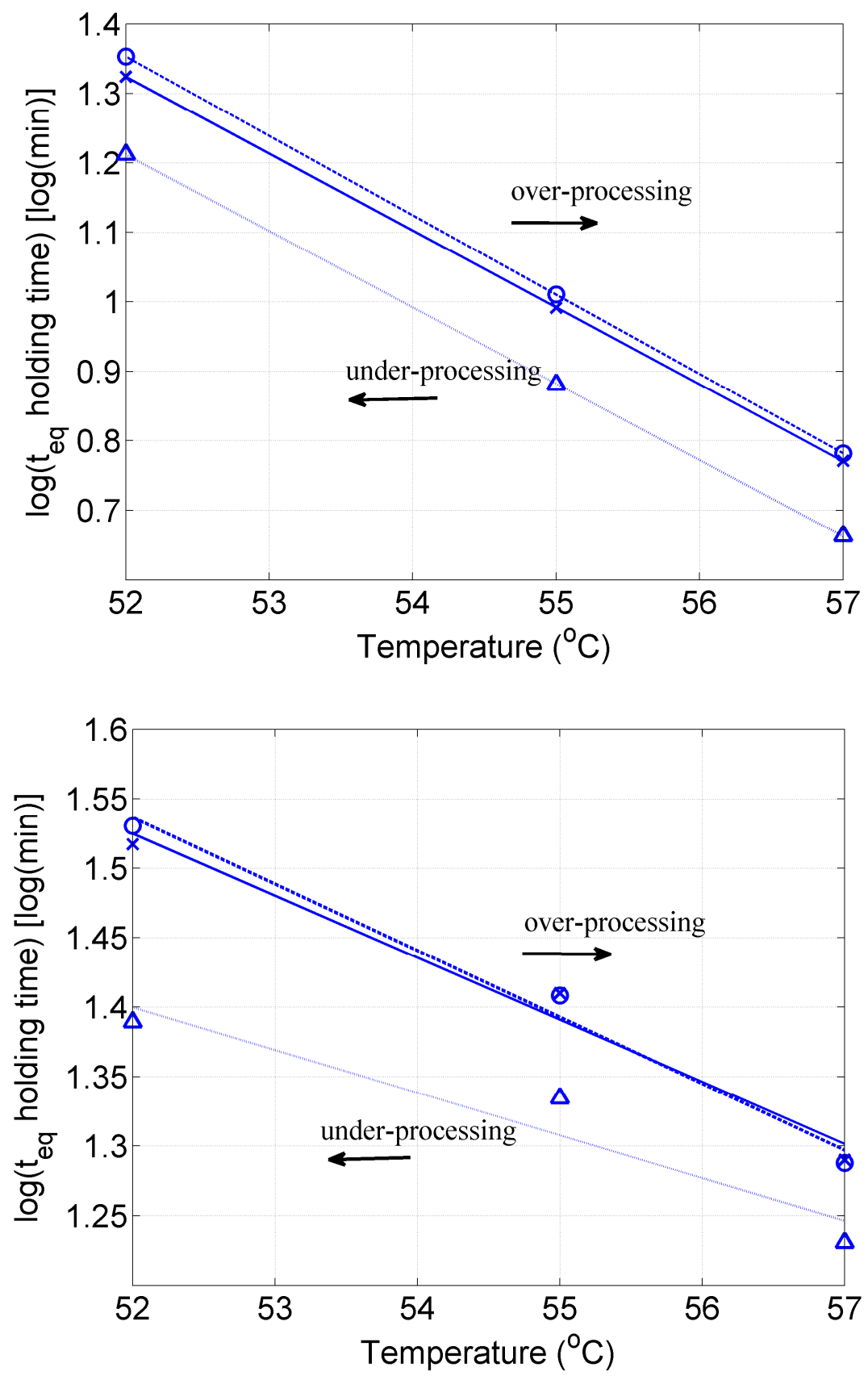

Figure 3. Derivation of equivalent time and temperature values (o: considering loglinearity for all data), ( $\Delta$ : considering log-linearity when taking the log-linear portion of the data), (x: considering non-log-linearity) when targeting at $4 \log$ (top Figure) and $6 \log$ reduction (bottom Figure) of L. innocua. Lines represent linear regression of the obtained data points (i) (considering non-log-linearity), continuous line, case (ii) (considering loglinearity when taking the log-linear portion of the data), dotted line, case (iii) (considering log-linearity for all data), dashed line, respectively. 